\title{
Business and IT Design with SEAM: an Illustration with the PhD Hiring Process at École Polytechnique Fédérale de Lausanne
}

\author{
George Popescu, Gorica Tapandjieva, Alain Wegmann \\ Systemic Modeling Laboratory (LAMS) \\ École Polytechnique Fédérale de Lausanne \\ Station 14, CH-1015 Lausanne, Switzerland \\ \{george.popescu, gorica.tapandjieva, alain.wegmann\}@epfl.ch
}

\begin{abstract}
Companies seek to align their business with their IT. This alignment is important to maximize the return on their IT investment in their business. One major challenge is to develop models that can be understood by both business and IT stakeholders. Without such models, it is difficult for stakeholders to reach a shared understanding and to agree on what the issues and solutions are. We present a method called SEAM: it uses a systemic approach for representing business and IT organizations. With SEAM, stakeholders can quickly develop an understanding of the problem and gain knowledge on how to address it. This improves the success rate of business and IT projects.
\end{abstract}

Keywords: systems thinking, business and IT alignment, enterprise architecture, business design.

\section{INTRODUCTION}

The Systemic Enterprise Architecture Methodology (SEAM) is used to describe and qualify project ideas in the field of business services and IT services. SEAM incorporates concepts from: requirements engineering [11], business and IT alignment [8], enterprise architecture [14] and business strategy [13]. It is used both in consulting and teaching.

This paper is based on a real project and workshops run at our university, the École Polytechnique Fédérale de Lausanne (hereafter EPFL).

EPFL is a fast-growing university with very distributed resources involved in the operation and development of IT systems. The IT organization within EPFL is decentralized and faces demands for fulfilling an increasing number of IT projects. The major challenge is to manage this demand with an IT budget that is not increased proportionally with the number of projects. We address this challenge by promoting a service-oriented metaphor to foster the collaboration between the teams. Our goal is to define:

- Who will use the services offered by the service systems? What are the benefits of these services? This applies to business services and IT services.

- Which service systems implement these services? Should the services be done internally or outsourced? Which technical architecture could simplify their realization?

- What process, application, or technical infrastructure should be obsoleted or simplified in the existing business and IT landscape?

Our proposed service view gives a concrete way of showing who provides services and who implements them. It is developed as an alternative and complements the traditional organizational view (i.e., org chart), which is inspired mainly by the accounting structure. We use SEAM to build this service view.

After illustrating how our method is used, we present the principles on which SEAM is based:

- philosophy, mainly systems thinking, to explain how people perceive reality, issues and solutions.

- formal methods, to explain how to model service systems, behavior and motivations.

In this paper, we illustrate the relations between these principles and the case study.

In the related work, we compare SEAM and the existing enterprise architecture (EA) methods.

The paper is structured as follows: Section 2 case study; Section 3 theoretical foundations; Section 4 related work.

\section{PhD Hiring Process CASE Study}

At EPFL there are 10,000 enrolled students, of which 2000 are $\mathrm{PhD}$ students. Given the average duration of 5 years for obtaining a $\mathrm{PhD}$ degree, roughly $400 \mathrm{PhD}$ students are hired annually. To illustrate the service view we want to promote, we chose the $\mathrm{PhD}$ hiring process. The process is well known at the EPFL central services and there is no plan to change it. The purpose of work is at the meta-level: to develop the service awareness, and not to actually change the processes (which is more a "by-product" of our workshops). To develop this service understanding, we organized a series of workshops.

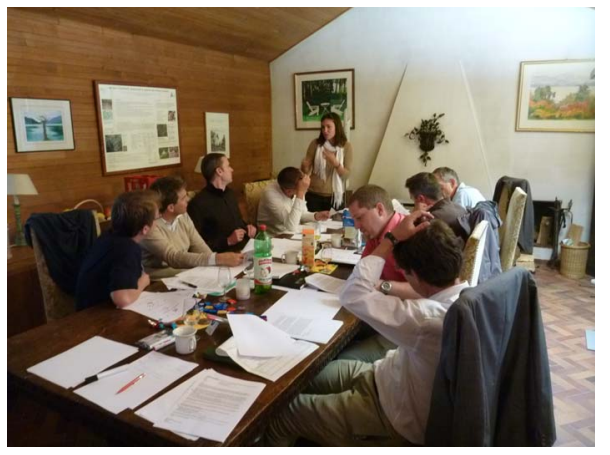

Figure 1. Workshop session in which the existing $\mathrm{PhD}$ hiring process is anlayzed.

The workshop illustrated in Fig. 1 comprised IT group managers, together with one professor and one $\mathrm{PhD}$ student, who experienced the process. In this workshop, we gave a 
sequence diagram describing the $\mathrm{PhD}$ hiring process and the actual documents of a process instance. The goal of the participants was to develop a model of the existing process situation. We illustrate the four typical phases that encompass a SEAM project: service system identification, analysis of the situation as-is, identification of the issues and design of the solution. Only the first three phases were done in the workshop. Typically, the design is done in a follow-up workshop. Our experience shows that people need to integrate the results of the analysis before working on designing solutions.

\section{A. Service Systems Identification}

In the $\mathrm{PhD}$ hiring process, there are two important service systems, the Academic Affairs and the Human Resources units. They host two major applications: ISAcademia and SAP, respectively. These service systems belong to the EPFL \& the world, as illustrated in Fig. 2. We chose this name for the broader service system that represents the overall project context. To make the model simpler, we do not differentiate between the actors within and outside EPFL. This holds, as the end user within EPFL (i.e., the professor) and the one outside EPFL (i.e., the applicant) need to get the same kind of services (e.g., simple to use).

We present a process model, a cleaned-up version of the one developed in the workshop. The process has 3 subprocesses: Registration, Selection and Employement (Fig. 2). They are represented inside the EPFL \& the world system. In a SEAM model, we purposely do not show the details of the processes and services, to avoid being caught in discussing details. We are more interested in broad issues and solutions. Our main focus is identifiying stakeholders, as well as understanding their responsibilities, the issues and the solutions. The descriptions of the three sub-processes are:

Registration. The sub-process begins when an Applicant uses the Registration service from the Academic Affairs to fill out his application record and upload his documents to IS-Academia (Fig. 2A\&B). IS-Academia is the academic management application of EPFL. The Registration service is implemented by the Registration process within the Academic Affairs (Fig. 2A). IS-Academia is one of the actors of this process. We represent processes with hexagons (Fig. 2A\&B). The dashed line denotes that the physical Documents on the Applicant side are the same as those uploaded to IS-Academia. The purpose of this subprocess is to decide who is admissable; we do not show how this decision is taken. This sub-process ends with the Doctoral School Administrative Assistant sending all applicants an e-mail to inform them whether they are admissible or not.

Selection. After having identified admisssable applicants, the Professor organizes interviews with his candidates of choice. The matchmaking part of the process, between applicants and professors, is not supported by any existing IT application. The Professor and the Lab Secretary use IS-Academia only to read Application Records and to insert some additional notes about the Applicants they are interested in. The Professor selects an Applicant and informs the Lab Secretary (e.g., phone) of his choice. Then the Lab Secretary informs the Doctoral School Administrative Assistant (e.g., e-mail) and requests the preparation of an Admission letter confirming that the selected candidate will be hired by the Professor's lab. This physical letter has to be signed by the Doctoral School Director and the Professor hiring the Applicant (Fig. 2C). This is a key document in the actual hiring. The Lab Secretary, asks the Applicant (now a future $\mathrm{PhD}$ student) for a scan of the usual Documents required for the contract preparation (CV, passport copy, etc.). Some of these documents are the same as the ones uploaded in ISAcademia in the first part. Together with the Admission letter, the documents are sent to the HR Assistant.

Employment. At this stage, the HR Assistant prepares the contract and arranges for any visa application needs. Once the contract is ready, it is sent for signature to the future $\mathrm{PhD}$ student. At this time a new record in SAP is made for him. From this point on, the employment record of the PhD student is in SAP, and his academic record is in ISAcademia. In the meantime, the Lab Secretary takes care of the student's accreditation. The Doctoral Assistant informs the Applicant about social events, and language courses whereas the student prepares for his arrival in Switzerland: finds an apartment, registers for language courses, etc.

\section{B. Issues Identification}

We identified the $\mathrm{PhD}$ hiring issues through our discussions with the workshops participants. The issues are marked with an exclamation ark in Fig. 2. The following three issues were selected as the most significant.

Duplicated Application documents. The applicant has to submit his Application documents twice (Fig. 2A).

Business: Part of the process is done manually: some documents are sent in physical format to the Lab Secretary, whereas some others are uploaded to IS-Academia and SAP (Fig. 2B).

IT: There is no application to support document management; IS-Academia and SAP are not linked, so information does not circulate from one application to the other (Fig. 2B\&C).

No visibility for Applicant and Professor of the overall process. The Applicant does not known when he will receive the contract. This would be useful for him to plan his relocation. The Professor does not know if his future PhD student has received the contract and when he can legally start working (Fig. 2A).

Business: The Lab Secretary might be on vacation or forget about certain documents to be sent out to the HR assistant (Fig. 2A\&C).

IT: There is no application to summarize the $\mathrm{PhD}$ hiring progress (Fig. 2B\&C). 


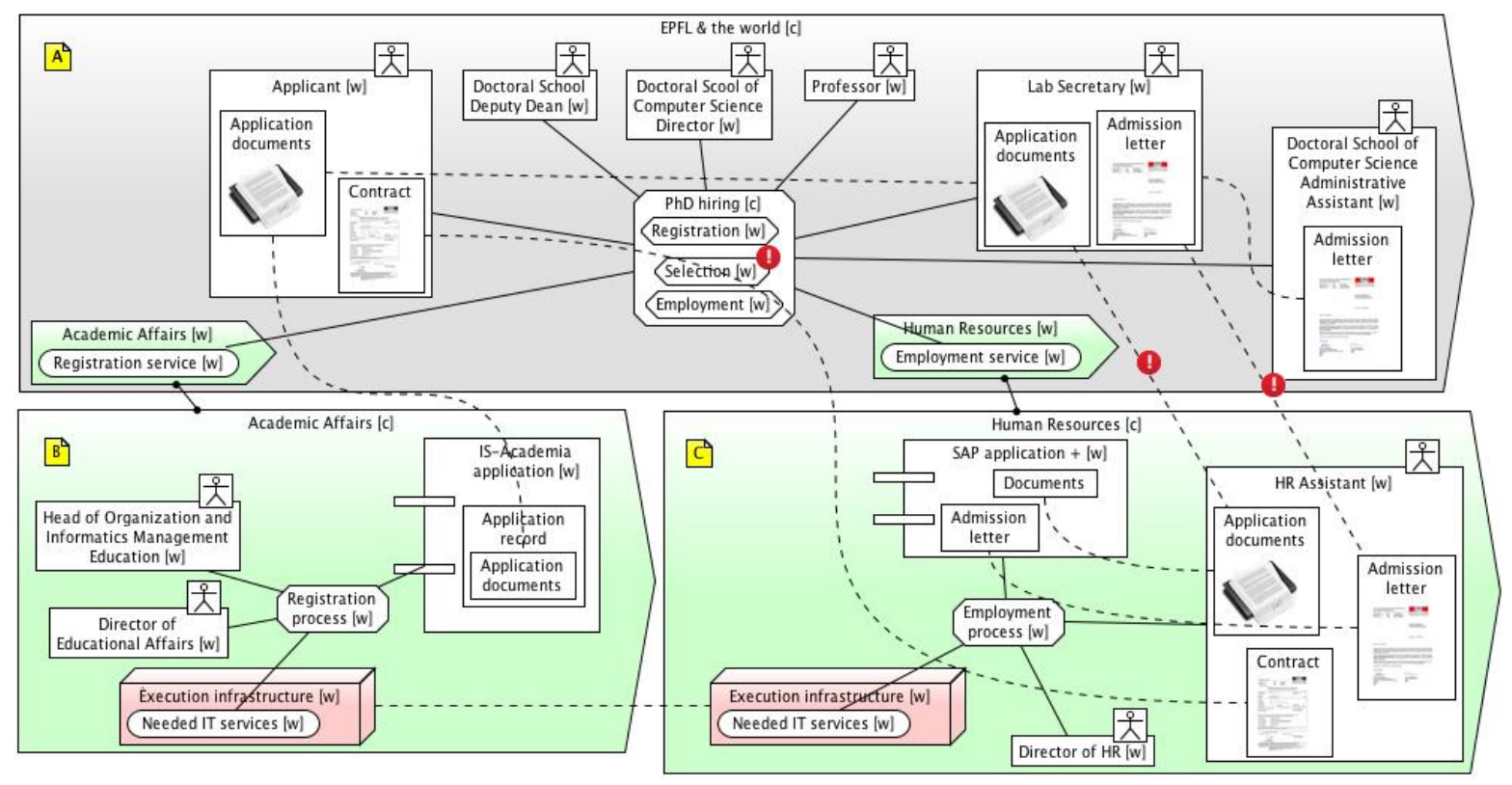

Figure 2. Behaviour as-is model of the current $\mathrm{PhD}$ hiring process

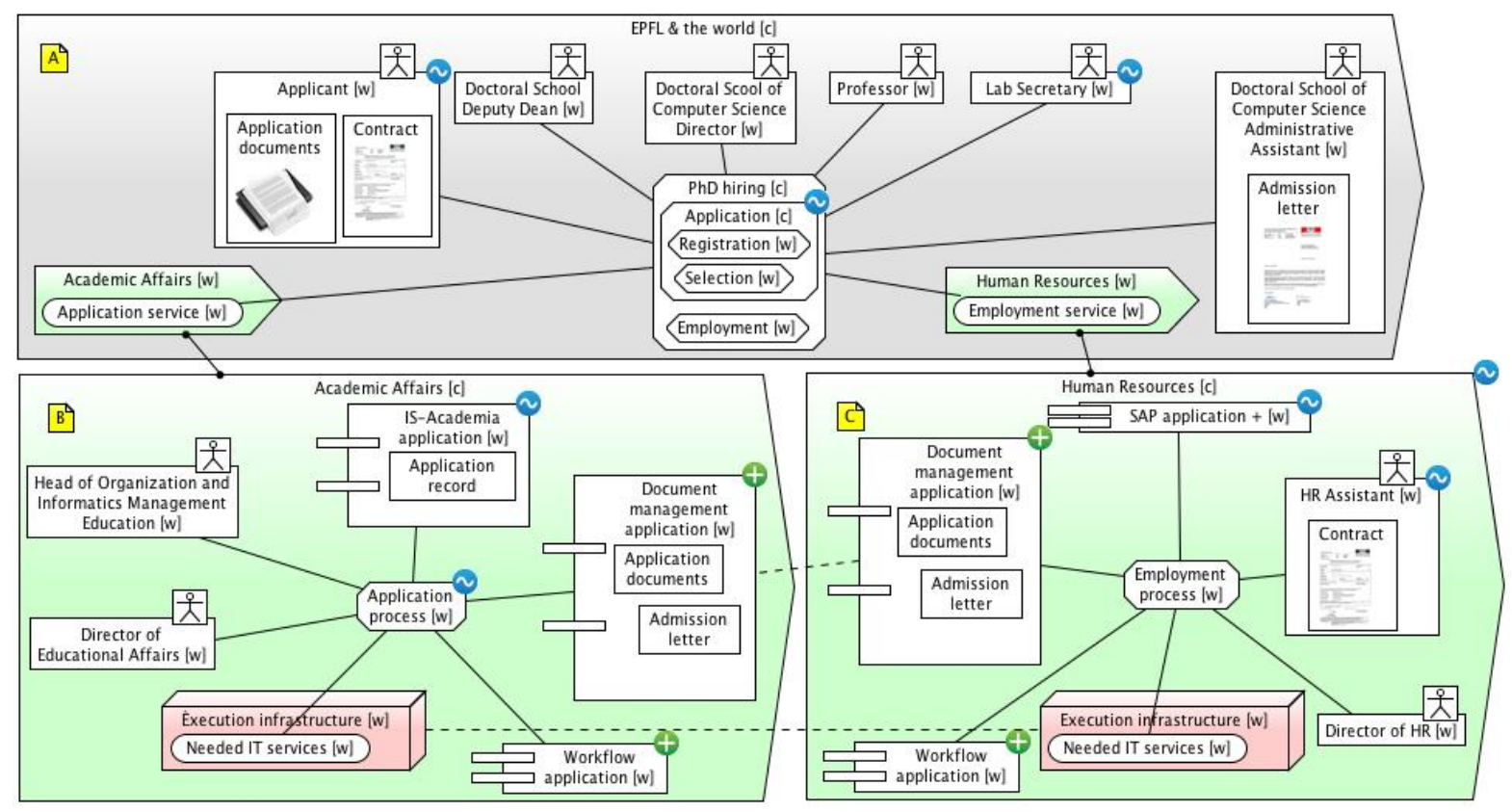

Figure 3. Behaviour to-be model of solution (A): Process automation

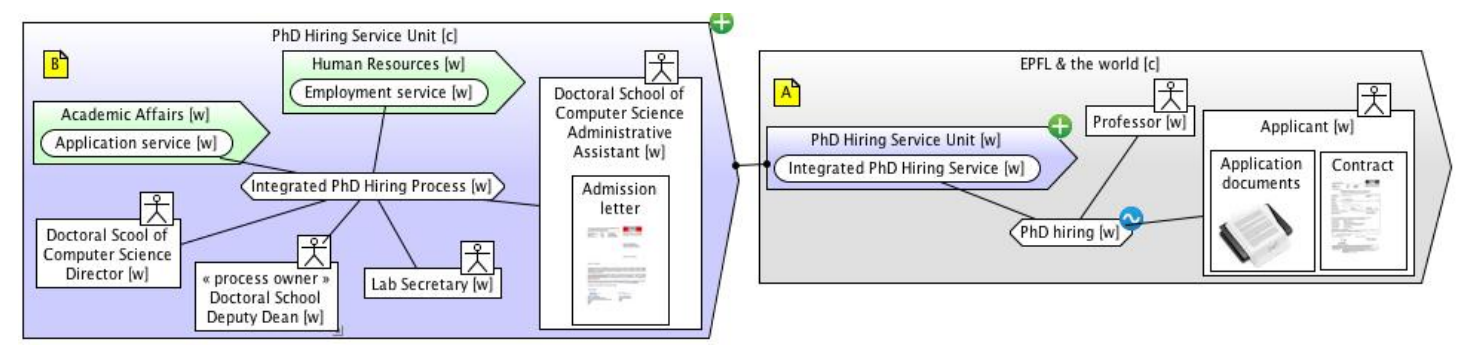

Figure 4. Behaviour to-be model of solution (B): Business activity monitoring 
Unacceptable effort as quality of service (QoS). The hiring time up to contract in-hand is unknown (Fig. 2A). The Applicant does not have an estimate of the time required between acceptance and formal hiring. The process duration can take between 2 to 6 months. As the applicant does not receive any feedback, he might accept an offer from a competing university.

Business: There is no support for the Selection subprocess (Fig. 2A). The Academic Affairs and the Human Resources ensure only Registration and Employment services (Fig. 2A).

IT: There is no service level agreement (SLA) defined for the process duration (Fig. 2A). An SLA is a contract between business and IT people on non-functional requirements related to a service [4].

\section{Solution Design}

We present two solutions: process automation and business activity monitoring.

Process automation: To address the first two issues, we (1) assign the Selection sub-process to a service system, (2) add a workflow application, and (3) we add a document management application. In Fig. 3, we group the Registration and the Selection sub-processes into the Application sub-process that is supported by the Academic Affairs. Adding the same workflow application in the Academic Affairs and in Human Resources can provide process automation. A Document Management Application can store the master documents and provide them to both IS-Academia and SAP. The Workflow application can provide a simplified view of the process for the Professor and the Applicant. All of these applications can work together with a linking and automation technologies [9].

Business activity monitoring: In order to insure the quality of service (QoS), we need to define an SLA for the Integrated PhD Hiring Service. To have the SLA, we need a service system that provides the integrated service. In our case, we define the PhD Hiring Service Unit, which is the service system that will be responsible for maintaining the SLA (Fig. 4). This service system includes the Academic Affairs and the Human Resources and provides an integrated service to the two key stakeholders: the Professor and the Applicant. This unit provides the Integrated PhD Hiring Service to the Applicant and the Professor. As all processes are linked to one organization, the PhD Hiring Service Unit is responsible for ensuring the SLA of the hiring process. This enables us to assign a process owner responsible of the overall service [9].

\section{THEORETICAL FOUNDATIONS OF SEAM}

Generally, all methods have principles that explain why they require specific activities. Most often, such principles are implicit. In SEAM, we make these principles explicit. For example, many methods are based on the assumption that people agree on what exists in a company, but actually they do not. One of the SEAM principles states they need to explicitly agree on what exists.
All principles that define SEAM are captured in what we call a systemic paradigm [5]. The SEAM systemic paradigm is rooted in the Systems Inquiry defined by Banathy and Jenlink [1]. The SEAM systemic paradigm includes three parts: SEAM Philosophy, SEAM Theory and SEAM Methodology.

SEAM Philosophy explains how we perceive reality, how we model the perceived reality and how we make choices. SEAM Theory includes the theories used to build the models and to work with the models. SEAM Methodology defines how to run a SEAM project, which phases exist and what needs to be done.

In this section, we present some of the main principles of SEAM.

\section{A. SEAM Philosophy}

Systems Philosophy is the study, by using systems concepts, of how people think. A SEAM model is based on observations and perceptions. Each modeler defines one viewpoint that is valid and meaningful for him. Often, conflicting viewpoints are useful for developing a shared understanding. The organizational levels in a SEAM model enable the capture of different perspectives (business, organization, IT). Within a perspective, a consensus has to be reached between stakeholders. In our example, the workshop animator combined participants' viewpoints and developed SEAM models with their active involvement.

Banathy and Jenlink [1] identified three components of systems philosophy: epistemology, ontology and axiology:

- Epistemology describes the relationship between the model and the reality. It is often implicit.

- Ontology describes the model elements or method's vocabulary. It is usually explicit.

- Axiology describes the choices made by the modelers on what to model. It is usually implicit.

Epistemology. There are two main epistemological principles of SEAM:

1) Constructivism Principle. According to this principle reality is a social construction and does not exist as such. In our example, the workshop participants represent the EPFL \& the world as a hierarchy of systems, which includes the Academic Affairs, Human Resources, and the Execution Infrastructure (Fig. 2A\&B). Developing a model together enables the participants to develop a shared understanding. Designing the solution might require creating new service systems (Fig. 4). Thus, there is no general truth in SEAM models; the agreement is only achieved through the construction of the model itself.

2) Embodied Cognition Principle. According to this principle, knowledge is built on the emotional experience lived in the body. For example, in our models, we highlight the role of the Application letter and Documents (Fig. 2 and Fig. 3), which have an emotional significance to the participants (e.g., the Applicant and the Professor). 
During the PhD hiring workshop, SEAM models were built with real documents so that participants could relate to the specific facts they model. In the diagrams, we removed the real names but kept the functions and roles. In other workshops, we might keep the name of the people, and even (sometimes) add their pictures. Thus, the participants become much more engaged in the modeling process.

Ontology. The SEAM ontology includes vocabulary elements used to model the perceived reality. These are represented as service systems and, depending on the context, they are called: organizations, people, IT applications, etc.

We distinguish between model and diagram ontology.

1) Model ontology. A SEAM model is based on a hierarchy of service systems. We analyze the behavior or the motivation of the actors in the systems and even of the organizations themselves.

- Hierarchy. The fundamental element is the service system. Using a hierarchy of systems, we can represent what service is provided (by a service system as a whole, denoted as [w]) and how a service is provided (by a service as a composite, denoted as [c]). For example, in Fig. 4, we show the PhD Hiring Service Unit as a composite made of Human Resources and Academic Affairs as a whole. In Fig. 2, we can see how Academic Affairs is composed.

- Behavior. A service is the behavior of a service system as a whole; a process is the behavior of a service system as a composite (e.g., in Fig. 2A Academic Affairs [w] provides the Registration services [w], whereas in Fig. 2B Academic Affairs [c] contains the Registration Process [c]). Processes can be decomposed into subprocesses (e.g., in Fig. $2 \mathrm{~A} \mathrm{PhD} \mathrm{Hiring} \mathrm{process} \mathrm{[c]} \mathrm{is}$ decomposed into Registration [w], Selection [w] and Employment $[\mathrm{w}])$.

- Goal-Belief. We model the stakeholders' motivations by using beliefs and goals. The goal-belief representation is not included here. However, we could have modeled (1) the Applicant's need for a contract to apply for housing (belief) and (2) his action of looking for an apartment (goal).

2) Diagram. A SEAM diagram is drawn using the following specific principles:

- Explicit hierarchy. In Fig. 4, we see the hierarchy in which the service systems exist. Service systems are always represented in larger service systems that become their context. For example, EPFL \& the world [c] (Fig. 4A) is the larger service system. Inside EPFL \& the world [c], there is a $\mathrm{PhD}$ Hiring Service Unit [w] (Fig. 4A). Inside the PhD Hiring Service Unit [c], there are the Academic Affairs [w] and Human Resources [w] (Fig. 4B). We represent hierarchies in SEAM as boxes inside boxes (as opposed to using a composition relationship). With this principle, we put an emphasis on which concepts are or are not hierarchical, and we make explicit the context in which the concepts exist.

- Error-proof. The "poka-yoke" mistake proofing mechanism applied to SEAM consists of making implicit elements explicit, in order to prevent misunderstandings, e.g., two modelers using the same name for different concepts. For instance, using service systems in Fig. 2A, modelers understand that the Academic Affairs provides only the Registration service, and not Selection or Employment.

Axiology. The SEAM axiology refers to ethics: choices made about what systems to show, what alternatives to design, etc. The SEAM axiology also refers to aesthetics: how to make simple, practical and easy to understand models. For example, we model behavior as one model element and not a detailed process. This puts an emphasis on the goal to be achieved rather than on the details of the implementation. This is often cited as one of the key features of SEAM.

\section{B. SEAM Theory}

The theoretical foundations of SEAM are in General Systems Thinking (GST) [16] and in RM-ODP [15]. GST seeks to define general principles that can be applied to any phenomena across established disciplines. RM-ODP is an ISO software engineering standard that provides the underlying definitions for the SEAM concepts (e.g., object, behavior, state, property).

In developing the SEAM method, we were inspired by the Unified Modeling Language (UML). A partial set of the SEAM notation is similar to the UML notation [2]. The main difference is that we merged the UML diagrams into one SEAM diagram.

For the SEAM method, we were also inspired by the Catalysis [3] software development process. Some of the Catalysis main principles adapted in SEAM are the hierarchical modeling structure (systems' construction and systems' behavior), and localized and distributed actions (that matches services and processes).

\section{SEAM Methodology}

Most SEAM projects have four phases. They happen across multiple workshops and can be repeated when needed.

(1) Service Systems Identification. Workshop participants agree on which systems to model. In our example, this results in the Behavior as-is model (Fig. 2). We model a nested hierarchy of systems, i.e., the systems that compose EPFL \& the world.

(2) Issue Identification. Workshop participants identify the issues. They are annotated in the Behavior as-is model developed in the previous phase (Fig. 2).

(3) Solution Design. Workshop participants explore possible solutions by adding or removing stakeholders or applications, and changing processes or services. The goal 
is to design business and IT solutions. For instance, in Fig. 4 we define a new service system. Possible solutions are described in one or more Behavior to-be models (Fig. 3 and Fig. 4).

(4) Detailed Solution Implementation. In order to develop an implementation, we refine the Behavior to-be model(s). For example, contracts are written and business processes are specified in BPMN (so they can be executed). We do not show this phase in this publication.

\section{RELATED WORK}

SEAM can be compared with the following EA frameworks:

TOGAF is the most widely used EA framework [10]. The TOGAF meta-model is based on the vocabulary of different disciplines, thus it is extensive. As a systemic approach, SEAM has a simpler meta-model. We model generic elements by thinking in a generic way. TOGAF does not have any graphical notation, whereas SEAM does.

Zachman framework is the best-known EA framework [17]. One of the main differences between Zachman's framework and SEAM is the exhaustivity of the model. Zachman's framework is used to create an inventory of data, process, applications and actors within a company. SEAM focuses on modeling a specific project. We do not build exhaustive models, but represent only what is necessary to show issues and solutions.

In France, URBA-EA [7] is the most frequently used methodology for planning IT systems (hence the name). It includes four views: business process, functional, application and technology. In SEAM, by using system services as a whole and as a composite, we can have the same four views, and we can model additional views, such as a marketing-strategy view.

SEAM is also related to ITIL [4], the most widely accepted approach to IT service management. ITIL provides best practices for service strategy. SEAM is used to animate scoping workshops, to analyze requirements for defining service and operational level agreements and to define organizational and technical strategies to implement ITIL. As we can represent the ITIL concepts in a SEAM diagram, SEAM is fully compatible with ITIL.

\section{CONCLUSIONS}

SEAM is mostly used in early requirements phases in business and IT alignment projects. It enables stakeholders to agree on which service systems exist, on what the issues are and what the solutions should be. We described how SEAM is applied to the PhD Hiring process at EPFL through a series of phases that enable systems to be identified, issues to be analyzed and solutions to be designed.

The originality of SEAM is that the method considers that both the business systems and the IT systems need to be analyzed and designed, in parallel. Other methods usually consider business analysis as a prerequisite for IT design, without considering any business design. For such methods, the IT serves the business. In SEAM, the coevolution of business and IT serves the company.

We illustrate the foundations of SEAM through principles that enable the systematic and systemic design process of business and IT.

\section{REFERENCES}

[1] B. H. Banathy and P. M. Jenlink. Systems inquiry and its application in education. Association for Educational Communications and Technology, pp. 37-58, 2004.

[2] G. Booch, J. Rumbaugh and I. Jacobson. Unified Modeling Language User Guide. Addison-Wesley, 2005.

[3] D. F. D'Souza and A. C. Wills. Objects, Components and Frameworks with UML. The Catalysis Approach. AddisonWesley, 1999.

[4] ITIL: http://www.itil-officialsite.com.

[5] T. Kühn. The structure of Scientific Revolutions. University of Chicago Press, U.S., 2012.

[6] C. Larman. Applying UML and patterns. Upper Saddle River, NJ: Prentice Hall PTR, 2005.

[7] C. Longépé. The Enterprise Architecture IT Project: The Urbanisation Paradigm. Kogan Page Science, U.S., 2003.

[8] G. Regev et al. A Philosophical Foundation for Business and IT Alignment in Enterprise Architecture with the Example of SEAM. In the Proceedings of Business Modeling and Software Design, Noordwijkerhout, Netherlands, Springer, 2013.

[9] J.W. Ross, P. Weill, and D. C. Robertson. Enterprise architecture as strategy: Creating a foundation for business execution. Harvard Business Press, pp. 45-67, 2006.

[10] TOGAF, http://www.opengroup.org/togaf.

[11] A. Wegmann et al. Requirements Modeling in SEAM: The Example of a Car Crash Management System. In the Proceedings of Requirements Engineering, Comparing Requirements Modeling Approaches Workshop, Rio de Janeiro, Brazil, Springer, 2013.

[12] A. Wegmann et al. A method and tool for business-IT alignment in enterprise architecture. In Proceedings of the CAiSE, vol. 5. Citeseer, pp. 113-118, 2005.

[13] A. Wegmann et al. Early Requirements and Business-IT Alignment with SEAM for Business. 15th IEEE International Requirements Engineering Conference, New Delhi, India, 2007.

[14] A. Wegmann et al. Business-IT Alignment with SEAM for Enterprise Architecture. International EDOC Conference, 2007.

[15] A. Wegmann et al. Enterprise modeling using the foundation concepts of the RM-ODP ISO/ITU standard. Information systems and e-business management, pp. 397-413, 2007.

[16] G. M. Weinberg and J. Wiley. An Introduction to General Systems Thinking. Wiley New York, 1975.

[17] J. A. Zachman. The Zachman Framework and Observations on Methodologies. Business Rules Journal 5(11), 2004. 